\title{
Atypical Presentation of a Young Female Patient With Takayasu Arteritis: Case Report and Review of Literature
}

\author{
Divey Manocha ${ }^{\mathrm{a}, \mathrm{d}}$, Rahul Anand ${ }^{\mathrm{b}}$, Pankaj Mehta ${ }^{\mathrm{a}}$, Kuldeep Kumarc ${ }^{\mathrm{c}}$, Richa Dewan ${ }^{\mathrm{c}}$
}

\begin{abstract}
Takayasu arteritis is a chronic non-specific inflammatory disease mainly involving the aorta and its main branches and is a common cause of reno vascular hypertension among young Asian females. Homocystinurias are a group of seven clinically and biochemically distinct disorders that affect the metabolism of the amino acid methionine. We here by discuss an interesting case of a young lady with past medical history of stroke and tubercular lymphadenopathy who presented with fatigue, chronic abdominal pain and congestive heart failure. Her diagnostic work up revealed multiple manifestations supporting Takayasu arteritis along with history of stroke at young age with co existing marfanoid features. Clinical clues and further diagnostic work up raised the possibility of coexisting Homocysteinuria in our patient.
\end{abstract}

Keywords: Takayasu arteritis; Homocystinuria; Hypertension; Congestive heart failure; Cystathionine $\beta$-synthase

\section{Introduction}

Takayasu arteritis is a chronic non-specific inflammatory disease mainly involving the aorta and its main branches including the brachiocephalic, carotid, subclavian, vertebral, renal arteries, coronary and pulmonary arteries [1, 2]. Histologically, it presents as 'panarteritis', with intimal fibrous thickening, cellular infiltration and collagenous fibrosis in the media and thickened adventitia with cellular infiltration

\footnotetext{
Manuscript accepted for publication March 13, 2013

${ }^{a}$ Internal Medicine, SUNY Upstate Medical University, Syracuse, NY, 13210, USA

${ }^{\mathrm{b}}$ Infectious Disease, University of Utah, Salt Lake City, Utah, 84132, USA

${ }^{\mathrm{C}}$ Internal Medicine, Maulana Azad Medical College and Associated Lok Nayak Hospital, New Delhi, 110002, India

${ }^{\mathrm{d}}$ Corresponding author: Divey Manocha, 50 Presidential Plaza, Apt 908,

Syracuse, NY, 13202, USA. Email: diveymanocha@gmail.com

doi: http://dx.doi.org/10.4021/ijcp82w
}

around vasa vosorum [3-5].

Homocystinurias are a group of seven clinically and biochemically distinct disorders that affect the metabolism of the amino acid methionine. These are caused by reduced activity of cystathionine $\beta$-synthase, which reduces the conversion of homocystine to cystathione and thus leading to increased concentration of homocystine in blood and urine. Clinical features of homocystinuria include developmental delay/intellectual disability, ectopia lentis and/or severe myopia, marfanoid features, thromboembolism and acute stroke in young [6-9].

\section{Case Report}

A 17-year-old female presented to our institution with complaints of progressive shortness of breath, anorexia, fatigue, intermittent claudication, non radiating right upper abdominal pain of three month duration. There was no history of chest pain, syncope, palpitations, wheezing, cough, altered bowel habits or menstrual irregularities. Her past medical history was significant for acute left middle cerebral artery ischemic stroke with right sided hemiparesis at the age of 12 years. She also had tubercular lymphadenopathy at the age of 14 years which was treated successfully with anitubercular therapy. There was no family history of stroke at young age or any other inherited disorders. In the general physical examination, the patient had marfanoid habitus (upper to lower body segment ratio of 0.86 with arachnodactyly), mild pallor, jugular venous distension, bilateral lower extremity edema and tachycardia with feeble pulses $(1+)$ in bilateral upper extremities. Systemic blood pressure was $170 / 100 \mathrm{mmHg}$ in right arm supine position and 156/92 $\mathrm{mmHg}$ in left arm supine position. Abdominal examination revealed tender hepatomegaly $5 \mathrm{~cm}$ below costal margin and no abdominal bruits. Cardiovascular examination revealed a pan systolic murmur grade III/VI at apex with soft S1.Ocular exam was negative for ectopia lentis and the rest of the systemic examination was also unremarkable. Preliminary blood investigations revealed dimorphic anemia (hematocrit of $23.7 \%$ ) and elevated sedimentation rate $(97 \mathrm{~mm} /$ hour$)$. Chest X-ray revealed cardiomegaly with early interstitial edema in bilateral lung 


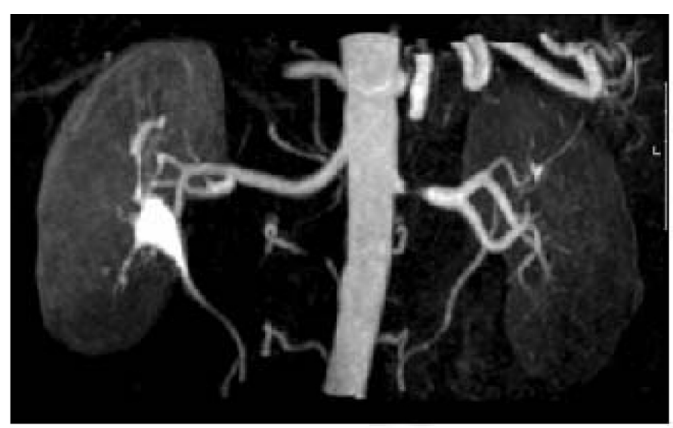

Figure 1. MRI Angiography of the abdominal aorta and its branches.

fields. Abdominal sonogram showed increased cortical echogenicity in bilateral kidneys with multiple calcific plaques in aorta. Doppler ultrasound of renal arteries showed decreased intrarenal vascularity, non visualization of left main renal artery and prominent calcific spots in aorta. Echocardiogram revealed severe mitral regurgitation and aortic regurgitation with left ventricular ejection fraction of $25 \%$. MRI angiography of the abdominal aorta and its major branches showed irregular outline of the aorta with irregular calcific plaques and intimal thickening of the left main renal artery (Fig. 1). At this stage of work up, presence of multiple manifestations supporting the diagnosis of Takayasu arteritis along with history of stroke at young age with co existing marfanoid features created a diagnostic and management dilemma for the primary team. Keeping a possibility of Homocysteiuria, Cyanide nitroprusside test was performed and was found to be positive. However, confirmatory genetic studies for homocystinuria could not be performed in accordance with the wishes of the patient. Thus a final diagnosis of Takayasu arteritis with renovascular hypertension and congestive heart failure was made. Possibility of Homocystinuria could not be ruled out. The patient was started on oral prednisone therapy for Takayasu arteritis. Oral Pyridoxine therapy besides folate and cyanocobalamin (vitamin $\mathrm{B}_{12}$ ) supplementation was initiated for possible homocystinuria. Supportive medical management for heart failure was continued. Eventually she underwent a percutaneous angioplasty and stent placement of the left renal artery with a favorable final outcome.

\section{Discussion}

Takayasu Arteritis is one of the common causes of reno vascular hypertension in young Asian females and is often related to renal artery stenosis. Aortic regurgitation and heart failure have been reported in upto $25 \%$ of patients with male: female ratio of 1:8 and mean age of presentation is around 26 years $[1,2]$. Acute ischemic strokes have been reported in $10-20 \%$ of these patients [10]. Intracranial stenoses in Takayasu arteritis could be due to either vasculitic involve- ment or a prior embolization into the vessel [11]. Involvement of cardiac valves and proximal arteries may also provide a source of embolism [12].

Diagnosis can be made using Modified Ishikawa's criteria or American College of Rheumatology criteria, which were fulfilled in our patient. Management includes combination of medical therapy with oral steroids and corrective vascular intervention in suitable cases [13-15].

Homocystinurias on the other hand, are a heterogeneous group of genetic disorders of autosomal recessive inheritance. Thromboembolism is the major cause of early death and morbidity in these patients. Carotid stenosis appears to have a graded response to increased levels of homocystine. Increased carotid plaque thickness has been associated with high homocystine and low B-12 levels [16, 17].

Two phenotypic variants are recognized; pyridoxine (vitamin B6) responsive and pyridoxine non-responsive homocystinuria. Pyridoxine is a cofactor of the enzyme cystathionine $\beta$-synthase and supplementation leads to prompt metabolic normalization in about $50 \%$ of the patients. Folate and vitamin $\mathrm{B}_{12}$ optimize the conversion of homocystine to methionine by methionine synthase, thus helping to decrease the plasma homocystine concentration [18, 19]. Diagnostic tests include cyanide nitroprusside test in urine, elevated levels of homocystine and its metabolites in blood and measurement of cystathionine $\beta$-synthase enzyme activity in tissue extracts. Treatment includes pyridoxine, folate and vitamin $\mathrm{B}_{12}$ supplementation in responsive subgroups and methionine restriction in diet $[8,18-20]$. Our patient had marfanoid habitus, dimorphic anemia, past history of massive stroke in the arterial territory and positive cyanide nitroprusside test which raise the diagnostic possibility of homocysteinuria.

Acute ischemic stroke is a unique overlapping vascular manifestation found in both these disorders which have an apparently unrelated pathophysiology otherwise. To the best of our knowledge, no report has been published in the world literature which shows any relation between Takayasu arteritis and homocystinuria. This case raises the possibility of a yet undiscovered link between these apparently unrelated diseases which needs to be investigated further.

\section{Declaration}

Authors declare no conflicts of interest. Authors declare that no financial assistance was taken from any source. Authors declare that they have no commercial or proprietary interest in any drug, device, or equipment mentioned in the submitted article.

\section{References}

1. Ishikawa K. Natural history and classification of occlu- 
sive thromboaortopathy (Takayasu's disease). Circulation. 1978;57(1):27-35.

2. Sharma BK, Sagar S, Singh AP, Suri S. Takayasu arteritis in India. Heart Vessels Suppl. 1992;7:37-43.

3. Numano F. Takayasu arteritis. Oxford textbook of medicine, 4th edn. Oxford: Oxford University Press 2001.

4. Numano F, Okawara M, Inomata H, Kobayashi $\mathrm{Y}$. Takayasu's arteritis. Lancet. 2000;356(9234):10231025.

5. Numano F. Vasa vasoritis, vasculitis and atherosclerosis. Int J Cardiol. 2000;75 (Suppl 1):S1-8; discussion S1719.

6. Mudd A. The Natural History of Homocystinuria Due to Cystathionine b -Synthase Deficiency, Americal Journal of Human Genetics, 37: 1-31, 1985.

7. Kelly PJ, Furie KL, Kistler JP, Barron M, Picard EH, Mandell R, Shih VE. Stroke in young patients with hyperhomocysteinemia due to cystathionine beta-synthase deficiency. Neurology. 2003;60(2):275-279.

8. Bracken P, Coll P. Homocystinuria and schizophrenia. Literature review and case report. J Nerv Ment Dis. 1985;173(1):51-55.

9. Miles EW, Kraus JP. Cystathionine beta-synthase: structure, function, regulation, and location of homocystinuria-causing mutations. J Biol Chem. 2004;279(29):29871-29874.

10. Kerr GS, Hallahan CW, Giordano J, Leavitt RY, Fauci AS, Rottem M, Hoffman GS. Takayasu arteritis. Ann Intern Med. 1994;120(11):919-929.

11. Klos K, Flemming KD, Petty GW, Luthra HS. Takayasu's arteritis with arteriographic evidence of intracranial vessel involvement. Neurology. 2003;60(9):1550-1551.

12. Johnston SL, Lock RJ, Gompels MM. Takayasu arteri- tis: a review. J Clin Pathol. 2002;55(7):481-486.

13. Liang P, Tan-Ong M, Hoffman GS. Takayasu's arteritis: vascular interventions and outcomes. J Rheumatol. 2004;31(1):102-106.

14. Sharma BK, Siveski-Iliskovic N, Singal PK. Takayasu arteritis may be underdiagnosed in North America. Can J Cardiol. 1995;11(4):311-316.

15. Arend WP, Michel BA, Bloch DA, Hunder GG, Calabrese LH, Edworthy SM, Fauci AS, et al. The American College of Rheumatology 1990 criteria for the classification of Takayasu arteritis. Arthritis Rheum. 1990;33(8):1129-1134.

16. Yoo JH, Chung CS, Kang SS. Relation of plasma homocyst(e)ine to cerebral infarction and cerebral atherosclerosis. Stroke. 1998;29(12):2478-2483.

17. Yap S. Classical homocystinuria: vascular risk and its prevention. J Inherit Metab Dis. 2003;26(2-3):259-265.

18. Yap S, Rushe H, Howard PM, Naughten ER. The intellectual abilities of early-treated individuals with pyridoxine-nonresponsive homocystinuria due to cystathionine beta-synthase deficiency. J Inherit Metab Dis. 2001;24(4):437-447.

19. Yap S, Boers GH, Wilcken B, Wilcken DE, Brenton DP, Lee PJ, Walter JH, et al. Vascular outcome in patients with homocystinuria due to cystathionine betasynthase deficiency treated chronically: a multicenter observational study. Arterioscler Thromb Vasc Biol. 2001;21(12):2080-2085.

20. Gan-Schreier H, Kebbewar M, Fang-Hoffmann J, Wilrich J, Abdoh G, Ben-Omran T, Shahbek N, et al. Newborn population screening for classic homocystinuria by determination of total homocysteine from Guthrie cards. J Pediatr. 2010;156(3):427-432. 